\title{
Modelling of Electro-mechanical Servo System Based on the Planetary Roller Screw Mechanism
}

\author{
Jianxin Zhang ${ }^{1,2}$, Chuanming $\mathrm{Du}^{1}$, Shangjun $\mathrm{Ma}^{1, *}$ and Geng Liu ${ }^{1, *}$ \\ ${ }^{1}$ Shaanxi Engineering Laboratory for Transmissions and Controls, Northwestern Polytechnical University, Xi' an 710072, China \\ ${ }^{2}$ Hubei Jiangshan Heavy Industry Co.,Ltd. , Xiangyang 441057, China
}

\begin{abstract}
Taking the electro-mechanical servo system as the research object, considering the contact stiffness, friction and clearance of the main components in the electro-mechanical servo system, the analysis model of the electro-mechanical servo system based on Planetary roller screw mechanism (PRSM) is established by using AMESim software. The results showed that the response speed of the system slowed down when the friction of PRSM was taken into account. The larger the clearance or the smaller the stiffness, the greater the fluctuation amplitude of the system response. After the controller was adjusted, the steady-state error of the system caused by the load force can be reduced quickly.
\end{abstract}

\section{Introduction}

The electro-mechanical actuator (EMA) is a core device of a fully electro-mechanical device. As an actuator for converting the rotational movement of the motor into linear motion, the planetary roller screw mechanism (PRSM) has the advantages of high bearing and high precision compared with the ball screw mechanism (BSM), it can be widely applied to the fields of industrial automation, ship and airplane braking [1].

The domestic and foreign scholars have made extensive research on the EMA, Liscouët et al. [2-3] proposed the EMA power transfer design criterion based on the simulation model. Ma et al. [4] established the finite element model of PRSM in EMA, and analyzed its dynamic characteristics, which provided a reference for studying the improvement of the overall performance of EMA. Huang et al. [5] established the EMA model to consider the non-linear factors such as clearance and friction, and set up the sub-system equations. Habibi et al. [6] analyzed the dynamic characteristics of EMA to control the rudder surface of aircraft. It showed that the dead zone caused by empty range and static friction was an important factor limiting the input and output characteristics of EMA, and the influence of dead zone on the system was reduced by using inner loop control strategy.

This paper considered the contact stiffness, friction and clearance of the main components in the electro-mechanical servo system, the analysis model of the electro-mechanical servo system based on the PRSM was established by using AMESim software.

\section{Introduction to EMA System}

Corresponding author: mashangjun@nwpu.edu.cn npuliug@nwpu.edu.cn

\subsection{The components of EMA system}

The composition of EMA in the rudder loop system of aircraft is shown in Fig. 1. The controller accepts the instructions from the flight control computer and drives the motor to move forward and backward, then reduces the speed and increases the torque through the gear device, finally converts the rotating motion of the screw into the linear output and drives the rudder surface to realize the corresponding action. At the same time, the current signal in the motor, the speed signal of the output shaft of the motor and the position signal of the rudder surface are all involved in the closed-loop feedback control.

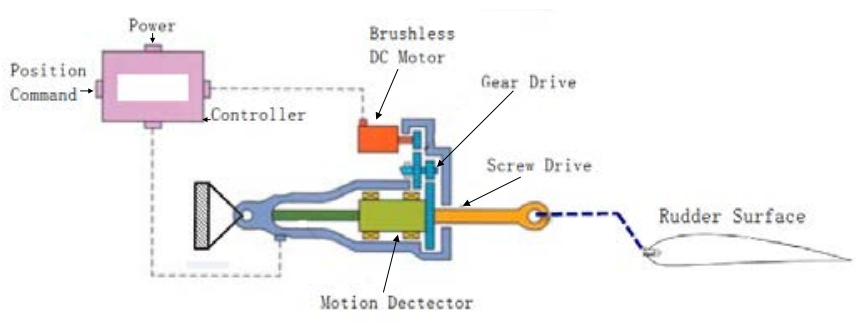

Fig. 1. Working principle of EMA in rudder loop system.

\subsection{The principle of EMA System}

The whole system model of EMA established in AMESim is showed in Fig. 2. The modelling of electro-mechanical system mainly includes the following parts: Region $a$ includes sine or given instruction input signal. Region $b$ and region $c$ are controller and motor model respectively. Region $d$ and region $e$ are the mechanical transmission models of gear pair and PRSM 
or BSM respectively. Region $f$ and region $g$ are equivalent stiffness and damping. The region $h$ is the rudder surface model.

\section{Model of motor and controller}

\subsection{Motor model}

The motor adopts $270 \mathrm{~V}$ permanent magnet brushless DC motor, and the DC motor model in the AMESim drive library are selected, as shown in Fig. 3. The parameters are shown in Table 1.

The relationship between the armature current of the motor $I_{c}$ and the input voltage $V_{c}$ is described by a first-order transfer function $G_{e}$.

$$
\begin{gathered}
I_{\mathrm{c}}=G_{\mathrm{e}}\left(V_{\mathrm{c}}-K_{\omega} \omega_{\mathrm{m}}\right) \\
G_{\mathrm{e}}=\frac{1 / R_{\mathrm{c}}}{L_{\mathrm{c}} / R_{\mathrm{c}} s+1}=\frac{1 / R_{\mathrm{c}}}{\tau_{\mathrm{e}} s+1}
\end{gathered}
$$

where $w_{m}$ is the output angular speed of the motor, $K_{w}$ is the back EMF coefficient, $R_{c}$ is the winding resistance of the motor, $L_{c}$ is the inductance of the motor winding and $\tau_{\mathrm{e}}$ is the electrical time constant of the motor. The torque generated by the motor is expressed as follows:

$$
T_{\mathrm{m}}=K_{\mathrm{c}} I_{\mathrm{c}}
$$

When the current is saturated, the following expression is obeyed:

$$
\begin{gathered}
T_{\text {peak }}=K_{\mathrm{c}} I_{\text {lim }} \\
T_{\mathrm{m}}=J_{\mathrm{m}} \dot{\omega}_{\mathrm{m}}+K_{\mathrm{mv}} \omega_{\mathrm{m}}+\frac{T_{\text {load }}}{i}
\end{gathered}
$$

where $J_{m}$ is the moment of inertia of the motor shaft,

\begin{tabular}{|c|c|c|c|}
\hline Parameters & Symbols & Value & Units \\
\hline Nut stiffness & $S_{N}$ & 108 & $\mathrm{~N} / \mathrm{m}$ \\
\hline Nut damping & $D_{N}$ & 8944 & $\mathrm{~N} /(\mathrm{m} / \mathrm{s})$ \\
\hline Nut mass & $M_{N}$ & 3 & $\mathrm{~kg}$ \\
\hline Screw nominal diameter & $d s$ & 20 & $\mathrm{~mm}$ \\
\hline Screw lead & $L s$ & 2 & $\mathrm{~mm}$ \\
\hline Screw contact stiffness & $S_{S}$ & 108 & $\mathrm{~N} / \mathrm{m}$ \\
\hline Screw contact damping & $D_{S}$ & 8944 & $\mathrm{~N} /(\mathrm{m} / \mathrm{s})$ \\
\hline Gear reducer ratio & $R_{G}$ & 3.33 & - \\
\hline $\begin{array}{l}\text { Gear transmission } \\
\text { efficiency }\end{array}$ & $f_{g}$ & 0.98 & - \\
\hline Actuator fixed stiffness & $S_{F}$ & $1.4 \times 107$ & $\mathrm{~N} / \mathrm{m}$ \\
\hline Actuator fixed damping & $D_{F}$ & 334 & $\mathrm{~N} /(\mathrm{m} / \mathrm{s})$ \\
\hline Actuator drive damping & $D_{D}$ & 3347 & $\mathrm{~N} /(\mathrm{m} / \mathrm{s})$ \\
\hline Actuator neutral length & $L_{a}$ & 500 & $\mathrm{~mm}$ \\
\hline Actuator shell mass & $M_{A}$ & 20 & $\mathrm{~kg}$ \\
\hline Actuator drive stiffness & $S_{D}$ & $1.4 \times 107$ & $\mathrm{~N} / \mathrm{m}$ \\
\hline Rudder surface inertia & $A$ & 20 & $\mathrm{~kg} * \mathrm{~m} 2$ \\
\hline Mass of steering surface & $M_{S S}$ & 2000 & $\mathrm{~kg}$ \\
\hline $\begin{array}{l}\text { Current loop feedback } \\
\text { channel gain }\end{array}$ & $G_{C}$ & 1 & - \\
\hline $\begin{array}{l}\text { Speed loop feedback } \\
\text { channel gain }\end{array}$ & $G_{S}$ & 0.15 & - \\
\hline
\end{tabular}
$K_{m v}$ is the friction coefficient of the motor, $T_{\text {load }}$ is the load torque and $i$ is the product of the reducer ratio of the gear and the screw.
Table 1. Parameters of EMA system
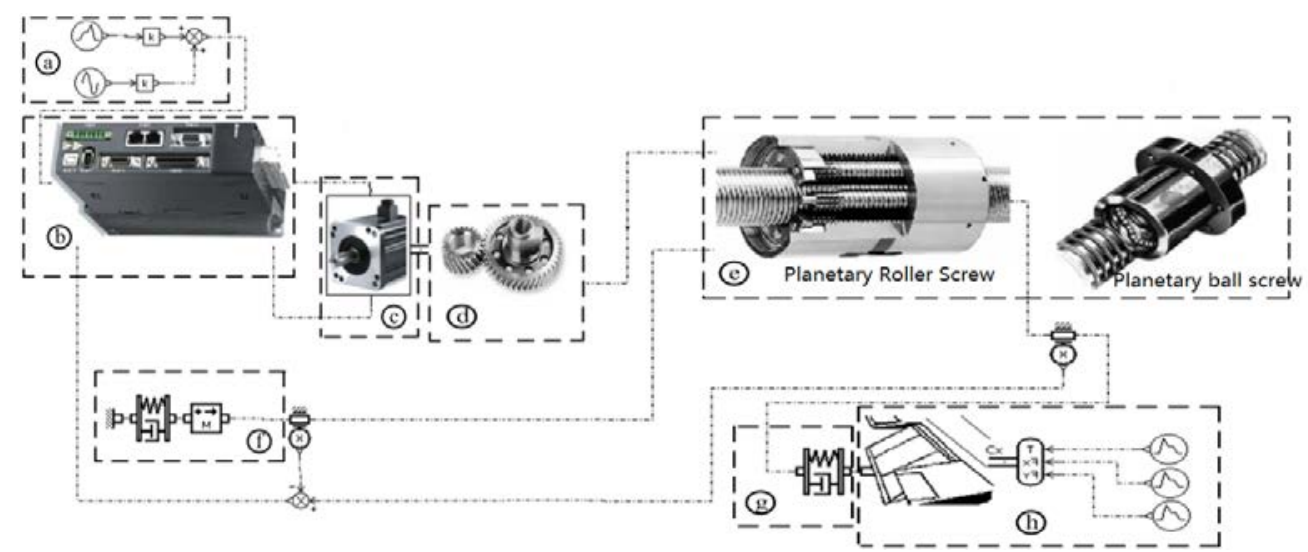

Fig. 2. EMA system model. 


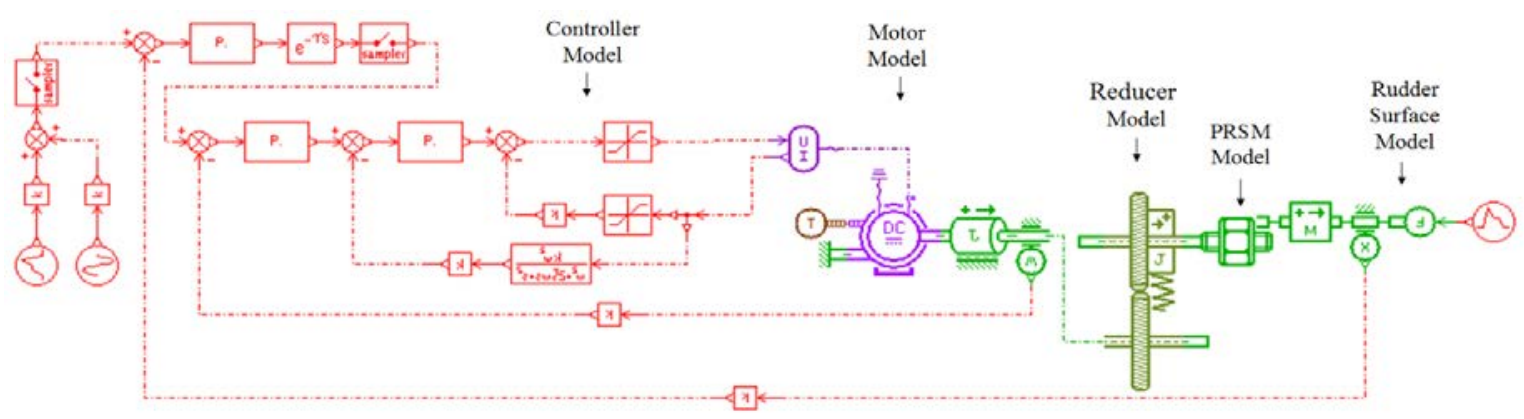

Fig. 3. AMESim simulation model.

\subsection{Controller model}

The loop of electro-mechanical action subsystem adopts three closed-loop control structures, the innermost loop is current loop, the outermost loop is position loop, and the middle loop is velocity loop, as shown in Fig. 3.

For the motor control system, the current loop is essentially the torque link, the introduction of the current loop in the control link has the following functions: By limiting the current of the motor bus, it can effectively protect the motor from damage due to excessive current in starting, braking, overload and blocking. Through proper control, the current loop can effectively reduce the electromechanical time constant of motor inner loop and broaden the bandwidth of speed loop, which lays a good foundation for the design of fast response speed loop controller.

The speed loop is a very important inner loop in the position servo system, which can provide system damping to improve the dynamic response characteristics of the control system, and adjust the frequency band of the speed loop can take into account the rapidity and anti-interference ability of the system. When the stiffness of motor and mechanical transmission structure is not large enough, the stiffness of the system can also be increased by the design of speed ring, but if the stiffness of speed ring is too large, which can easily cause mechanical vibration and lead to system jitter.

The position loop receives the position given instruction signal sent by the upper computer or the flight control computer, and measures the actual position of the steering gear through the position sensor, and controls the deviation signal between the position given and the position feedback, so that the actual output of the steering gear tracks the change of the instruction signal. The feedback loop of position loop has integral link, so it is only necessary to use proportional controller to improve the rapidity of the system and eliminate the steady-state error. The adjustment of the parameters of the proportional controller is finally determined by observing the steady-state error of the step response by the trial method.

In AMESim, the sampling frequency is set to $10 \mathrm{~Hz}$, and the load is added from $5 \mathrm{~s}$ to $10000 \mathrm{~N}$. The signal input is $0.1 \mathrm{~V}$, applied from $0.1 \mathrm{~s}$, and given 0 when $0 \sim$ $0.1 \mathrm{~s}$. The output results were disturbed by injecting $10000 \mathrm{~N}$ load force into the system at $5 \mathrm{~s}$, and recovered at 7s. as shown in Fig. 4.

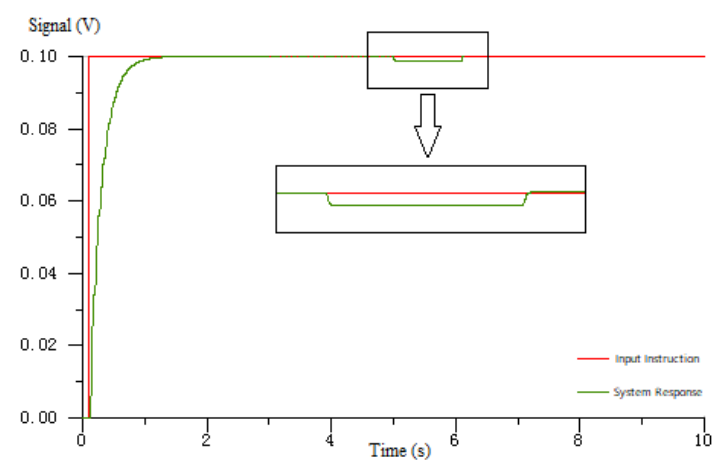

Fig. 4. Simulation results of motor and controller.

\section{The reducer model}

The reducer model is established in AMESim, as shown in Fig. 3. In this model, the contact stiffness, energy loss and clearance can be considered.

\section{The rudder model}

The hydrodynamic load on the rudder surface is mainly related to these factors: the area of the rudder surface, the flying altitude, the airspeed and the upwind angle of the rudder surface. During flight, the load torque of aerodynamics is the main load type of rudder surface. In AMESim, the rudder surface is equivalent to a concentrated mass block, as shown in Fig. 3.

\section{The PRSM model}

The contact stiffness, clearance, Coulomb friction coefficient and other parameters between the screw and the nut can be considered, the model is shown in Fig. 3.

\subsection{Stiffness impact of the PRSM}

The stiffness of the actuator is set to be $1 \times 10^{9} \mathrm{~N} / \mathrm{m}$, $1.5 \times 10^{9} \mathrm{~N} / \mathrm{m}, 2 \times 10^{9} \mathrm{~N} / \mathrm{m}$ respectively, as shown in Fig. 5. The simulation results show that when the system inputs the load force, the higher the stiffness value, the smaller the fluctuation amplitude, the more easily the steady state is achieved, and the smaller the steady-state error of the system. 


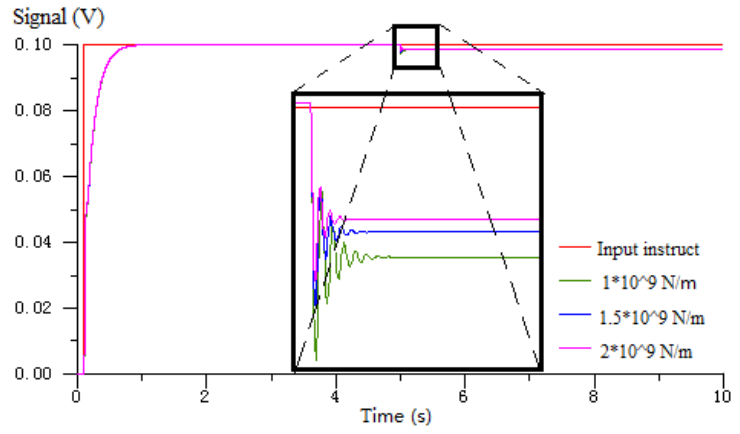

Fig. 5. Stiffness effect of PRSM.

\subsection{Impact of clearance in PRSM}

The clearance is derived from the machining and assembly error of the parts such as the PRSM, the bearing, etc. The clearance in the actuator is set as $0.001 \mathrm{~mm}, 0.01 \mathrm{~mm}$ and $0.1 \mathrm{~mm}$ respectively, as shown in Fig. 6. The results show that in EMA, the clearance has a significant influence on the control accuracy and stability of the system. The greater clearance, the greater amplitude of the system response, the higher frequency, the greater steady-state error.

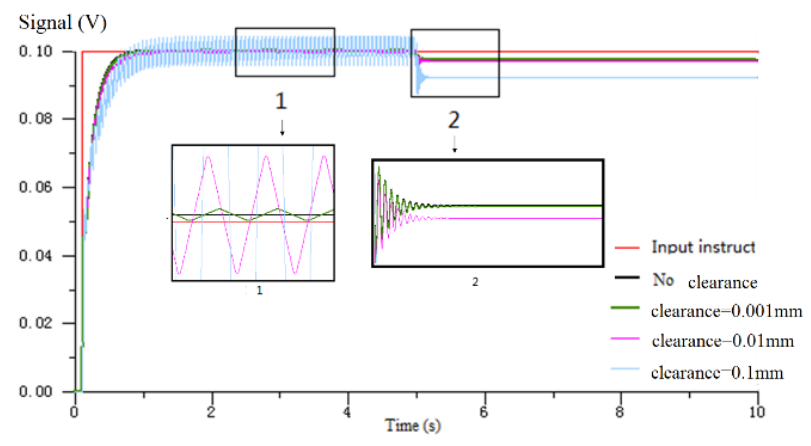

Fig. 6. Clearance impact of actuator.

\subsection{Friction effects of PRSM}

The formula of friction moment $F_{\text {fric }}$ is:

$$
F_{\text {fric }}=\left[F_{C}+F_{S} e^{\frac{-\left|\omega_{m}\right|}{\omega_{s}}}+\left|T_{\text {load }}\right|\left(c+d \operatorname{sgn}\left(\omega_{m} T_{\text {load }}\right)\right)\right] \operatorname{sgn}\left(\omega_{m}\right)
$$

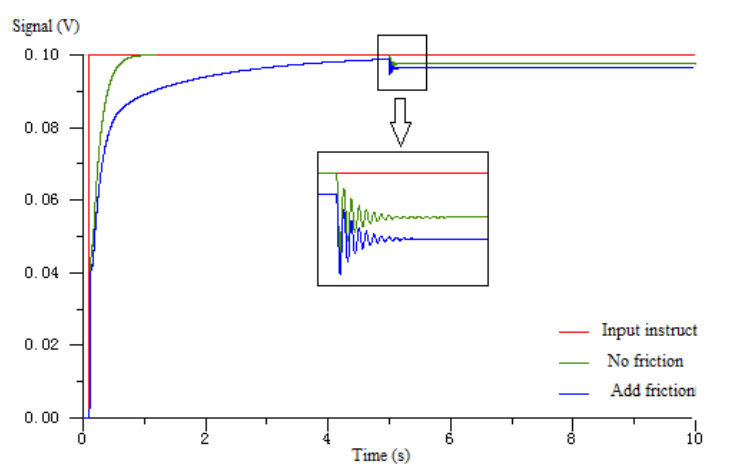

Fig 7. PRSM simulation results for friction effects where $F_{c}$ and $F_{s}$ are the torque produced by Coulomb friction and Stribeck friction respectively. The output moment of the motor $T_{m}$ is the sum of the friction moment $T_{\text {fric }}$ and the output moment of the load end $T_{\text {load }}$, $w_{s}$ is the reference speed, $c$ is the average coefficient of the external force influence, and $d$ is the quadrant determining coefficient.

The established AMESim model is shown in Fig. 3, and the simulation results are shown in Fig. 7. The results show that when considering the friction torque of PRSM, the response speed of the system slows down and the steady-state error is increased.

\section{Conclusions}

Through the simulation calculation, the conclusion is drawn as follows:

(1) when the controller is perfected, the steady-state error of the system caused by the load force can be reduced quickly.

(2) when the friction torque of PRSM is taken into account, the response speed of the system becomes slower and the steady-state error becomes larger.

(3) the larger clearance or the smaller stiffness value, the larger the fluctuation amplitude of the system response, the higher frequency and the greater steady-state error.

This research was supported by the National Natural Science Foundation of China (Grant No. 51875458), Key Project of National Natural Science Foundation of China (Grant No. 51535009) and the Fundamental Research Funds for the Central Universities (Grant No. 31020190504003 ).

\section{References}

1. S. J. Ma, G. Liu, R. T. Tong, Friction Heat Analysis of the Planetary Roller Screw Considering Load Distribution, Mech Based Des of Struc, 43, 164-182 (2015)

2. J. Liscouët, M Budinger, J. C. Maré, S. Orieux, Modelling approach for the simulation-based preliminary design of power transmissions, $J$ Mech Mach Theory, 46 (3), 276-289 (2011)

3. J. C. Maré, Dynamic loading systems for ground testing of high speed aerospace actuators, Aircr Eng Aerosp Tec, 78 (4), 275-282 (2006)

4. S. J. Ma, G. Liu, R. T. Tong, A new study on the parameter relationship of planetary roller screw, Math Probl Eng, Article ID340437, 29 pages (2012)

5. J. Huang, Y. Liu, X. H. Zhang, W. Guan, Z. Y. Song, Dynamic Modeling and Simulation of Electro-Mechanical Actuator Coupled with Nonlinear Factors, Proceedings of the 37th Chinese Control Conference, CCC. 2018, Wuhan. China, 3776-3780 (2018)

6. S. Habibi, J. Roach, G Luecke, Inner-loop control for electro-mechanical (EMA) flight surface actuation systems, $J$ Dyn Syst-T ASME, 130 (051002), 1-13 (2008) 